\title{
¡Hablemos en serio de renovación pedagógica!
}

\author{
Jordi Collet (Universitat de Vic-UCC)
}

\author{
Feu, J.; Besalú, X.; Palaudàrias, J.M. (Coords.) (2021) La \\ renovación pedagógica en España. Una mirada crítica y \\ actual. Madrid, Morata, 342 págs.
}

Las preguntas y los debates sobre el cambio en la escuela son consustanciales a su misma existencia desde la creación de los sistemas estatales de educación durante el siglo XIX. Pero también es cierto que, como en la vida, estos debates experimentan lo que la psicología del desarrollo llama periodos críticos o lo que Jaume Carbonell ha llamado las primaveras de debate pedagógico'. Sin duda, la década de los 2010 ha sido uno de esos periodos críticos o una de esas primaveras en las que, de forma colectiva, las escuelas e institutos, se han hecho preguntas educativas y han buscado formas diversas de dar respuesta a las mismas. De eso trata el libro coordinado por Jordi Feu, Xavier Besalú y J.M. Palaudàrias, profesores de la Universidad de Girona, que cuentan con una larga trayectoria de acción y reflexión educativa. Creo que este libro, más allá de la suerte de poder ser uno de sus autores, es altamente pertinente y oportuno porque analiza esta década de cambios e innovaciones y, a la vez, plantea una agenda clara y estructurada para avanzar hacia la renovación pedagógica. Precisamente el primer capítulo de Jordi Feu y Xavier Torrent, propone una clarificación entre los tres conceptos: el cambio, la innovación y la renovación (crítica) de las finalidades, las metodologías, la estructura y la organización, el currículum y los roles educativos en la escuela. Según mi parecer, se podría incorporar la dimensión de evaluación como central en todo proceso de cambio educativo. En todo caso, comparto con los autores que el cambio alcanza modificaciones en los métodos de enseñanza-aprendizaje, en los materiales, los recursos, etc. Mientras que la innovación, incluiría estos cambios, pero, además, transformaría los espacios y los tiempos tradicionales (lo que me gusta llamar la «gramática uno»: una hora, un grupo, una asignatura, un/a docente, un aula, etc.). La innovación implica transformar estructuras espaciales y temporales $y$, por ende, relaciones, grupos, currículums, etc. dentro de la escuela. Sin que ello conlleve, necesariamente, dos condiciones para que, según los autores, se pueda hablar de renovación pedagógica: que la innovación sea sistémica, es decir de todo el centro y de todas sus dimensiones y prácticas; que también transforme su relación con familias y comunidad; $y$, que incluya el replanteamiento del sentido y de la función de la educación escolar. Así, la renovación pedagógica se define como el proceso de transformación estructural y sistémico de la escuela y sus vínculos con familias y comunidad guiado por un cuestionamiento de sus funciones y sentido. Si, además, esta renovación se orienta explícitamente hacia la construcción de un mundo más justo, equitativo e inclusivo y contra

(1) https://diarieducacio.cat/les-tres-primaveres-pedagogiques/ 
las dinámicas segregadoras, autoritarias y competitivas, los autores proponen llamarla «renovación crítica». Una vez definidos los conceptos básicos, el libro discurre por diez capítulos que, desde perspectivas distintas, contribuyen de forma relevante a una reflexión sobre una década de debate pedagógico y, a la vez, proponen una agenda rigurosa para, según mi implicado parecer, avanzar hacia una renovación crítica.

El primero de estos capítulos es el de Javier Pericacho que, basándose en años de investigación, plantea un recorrido histórico por la renovación pedagógica en el Estado Español desde la Institución Libre de Enseñanza hasta la Ley General de Educación (LGE) de 1970. El segundo, de Jaume Martínez Bonafé, retoma el análisis histórico de Pericacho justamente en la LGE y lo lleva, de una forma crítica y bien argumentada, hasta nuestros días. Los dos me parecen claros, ricos, bien estructurados y aportan un marco de comprensión pertinente que encuadra y enlaza con el esto de textos. El tercer capítulo, de José Contreras y Remei Arnaus vuelve a poner de manifiesto un tema que la autora y el autor llevan trabajando desde hace decenios: el de la educación alternativa. Precisamente en el análisis que realizan de las educaciones fuera del sistema escolar formal, proponen mirarlas como espacios de apertura pedagógica que, más allá de su valor como experiencias concretas, han inspirado y alentado (al menos parcialmente) las distintas apuestas por la innovación y la renovación pedagógica. $Y$, según su parecer, todavía lo hacen y lo podrán seguir haciendo por su potencial experimentador, transgresor y de punta de lanza que les da trabajar en los márgenes del sistema. Desde mi punto de vista, uno de los capítulos más sugerentes del libro es el de Xavier Laudo en el que se busca «cartografiar» las pedagogías del siglo XXI.
Laudo, siguiendo la metáfora que Bauman propuso para entender la segunda modernidad como un paso de la modernidad sólida a la líquida, propone analizar cuatro grandes tipos de pedagogías: sólidas, gelificadas, liquidas y gaseosas. Por pedagogía sólida, Laudo entiende aquellas que, situadas a derecha o izquierda del espectro ideológico, «se sustentan en una verdad fuerte basada o bien en la conservación de la tradición o en un progresismo hacia la promesa de una utopía social» (p. 141). Además «los métodos de esta pedagogía suelen ser sólidos en el sentido de rígidos y sus fines no admiten discusión» (p. 141). Por pedagogía gelificada, Laudo entiende «una derivada espuria y engañosa de la pedagogía sólida» (p. 143), ya que estas pedagogías "pretenden ser y "venderse" como líquidas y adalides de la libertad, pero no lo son» (p. 144). Así, bajo conceptos relevantes, pero realmente vacíos de contenido como poner al alumno en el centro, el autoconocimiento, los proyectos, las inteligencias múltiples, el trabajo cooperativo, las TIC, la neurociencia, etc., se acaba construyendo una pedagogía que parece que «lo tiene todo», pero solo para gustar a todo el mundo, esquivar las críticas y centrarse en la excelencia, la distinción, la segregación y la (supuesta) eficacia que es lo que realmente buscan. Según Laudo, algunas de las iniciativas pedagógicas de la pasada década, podrían considerarse como gelificadas. La pedagogía líquida «es un discurso pedagógico donde la única certeza es educar de forma flexible y respetuosa con la esencia (sic) de cada persona y su contexto» (pp. 149-150). Y pone como ejemplos la pedagogía sistémica y la Waldorf centradas en «que cada persona se encuentre por sí misma lo que quiere hacer y cuál es su verdad y lo que le da sentido en el mundo» (p. 152). Finalmente, la pedagogía gaseosa es aquella que «no tiene más sentido que la pura adaptación automática a la novedad, a 
menudo de forma totalmente acrítica (...) una de sus mayores características es la falacia innovacionista, innovar por innovar sin una finalidad clara o sostenida en el tiempo» (p. 153). Este capítulo acaba presentando las cuatro categorías como herramientas para pensar críticamente la renovación pedagógica, esto es, utilizando la metáfora propuesta por Foucault, más como un destornillador o un martillo a utilizar para reflexionar y actuar, que como una verdad a creer y/o seguir.

El siguiente capítulo, escrito por Gino Ferri, se centra en analizar los procesos de aprendizaje desde el punto de vista de la niña o el niño. Ferri, que habla con gran libertad desde un constructivismo real, radical y global (y no desde versiones reducidas, low cost, individualistas o en tráileres, como a veces se nos presenta), recupera la visión del infante como un ser relacional y comunicativo que construye conocimiento y crea significados del mundo. Aquí, aprender es siempre algo contextual, relacional, creativo y significativo, personal y colectivo, escolar y comunitario. Y el diálogo que abre sobre cómo la renovación pedagógica debe promover ese tipo de aprendizajes me parece una muy buena conversación entre Vigostki, Freire y Freinet. Sin duda, tres de los autores más sugerentes del siglo $x x$ con quién siempre apetece sentarse a tomar un buen café (o infusión). Albert Torrent, en su capítulo sobre el rol del docente en la renovación pedagógica, recupera también la tradición de Freinet y las aportaciones en esta línea de Sebastián Gertrudix para plantear una escuela que sea más un taller que una fábrica (p. 205). Hace algunos años, y siguiendo los preciosos análisis del sociólogo Richard Sennett (2006) sobre los talleres de violines de Stradivarius y Del Gesu, intenté plantear una idea parecida (Collet, 2011). Concebir y practicar la escuela como un taller de artesanía y a cada niña y niño como un violín precioso me parece una metáfora interesante para (re)plantear una agenda de renovación pedagógica. Especialmente cuando, como hemos visto, bajo nombres bonitos y conceptos relevantes, potentes corrientes educativas plantean transformar las escuelas (y las universidades) en espacios de transmisión educativa pura y dura. Una transmisión, eso si, altamente eficaz y eficiente que concibe a los infantes (o a los estudiantes universitarios) a veces como paquetes de Amazon a entregar (a un mercado laboral infernal) y a veces como aplicaciones de Google (a desarrollar - manipular). Así, Torrent propone que el rol del/la docente sea el de acompañante. Un acompañante que, siguiendo el trabajo de Rancière en El maestro ignorante (2003), debe partir «de la igualdad de las inteligencias para con sus alumnos, eso es, la razón de dos iguales». El capítulo octavo versa sobre la organización horizontal y la dirección compartida, es decir, sobre como promover renovaciones pedagógicas que permitan avanzar hacia escuelas democráticas y que cuidan de lo común. Este capítulo tuve la suerte de poderlo escribir yo mismo. En este sentido, y también siguiendo a Rancière, creo que una buena escuela (o la renovación pedagógica crítica) no tienen que ver con buscar una buena definición sobre ello como quien busca capturar una verdad. Sino con la lucha por el significado concreto, práctico y real de esa expresión. Y, en esa misma línea, lo que propongo en el capítulo es que no puede haber renovación pedagógica sin afrontar la pregunta por el poder ( $p$. 230). Ante planteamientos neutrales, técnicos y tecnológicos que disponen de un modelo de transformación educativa neutro, lineal, top-down y automático, es decir falso como en la pedagogía gelificante o gaseosa en la cartografía de Laudo, propongo que en toda renovación pedagógica se afronte explícitamente la pregunta 
por el poder. Entendiéndolo no de la forma tradicional (como opresión y coacción), sino como un poder productivo y positivo. Es decir, como los mecanismos, las técnicas, las dinámicas y, sobretodo, las relaciones sociales que permiten realmente que las cosas pasen y cambien. Entendiendo no un poder sobre, sino un poder para, un poder de, un poder con. Desde esta perspectiva, desde una mirada foucaultiana, la pregunta por el poder pasa a ser un proceso abierto de repolitización de todo lo educativo para plantearnos explícitamente para qué educar, como gobernar democráticamente esa educación y con quién realizarla. Para acompañar esa repolitización, esa pregunta por el poder, propongo cinco pistas ( $5 \mathrm{C}$, siento el reduccionismo), por si son de utilidad en esos procesos que cada escuela, cada instituto y cada sistema educativo pueden plantear. Estas herramientas son: entender toda renovación como un camino, como un proceso, como un horizonte a construir en común; que el conflicto forma parte inextricable de ese proceso y que una escuela es más fuerte como más pluralidad, diversidad y conflicto es capaz de albergar; que toda renovación, en la misma línea que el texto de G. Ferri, debe ser contextual, enraizada $y$, por lo tanto, única; una renovación que debe ser en común, colectivamente, ya que la renovación es un nosotros/as; y finalmente, toda renovación debería ir, según mi parecer, en la línea de la educación como bien común, como plantea el próximo informe de la UNESCO que se publicará en noviembre de $2021^{2}$.

El capítulo de Guillermo Bautista, Anna Escofet y Marta López se centra en analizar el ambiente y los espacios de aprendizaje como elementos centrales de la renovación educativa, un debate que no se puede esquivar a la hora de transformar la gramática profunda de las escuelas. En este mismo sentido, el capítulo de Heike Freire nos plantea la necesidad de educar para amar la tierra, en un momento en que el informe del panel de personas expertas de la ONU sobre cambio climático no deja lugar a dudas: o cambiamos como vivimos o el desorden climático nos obligará a ello con altos costes humanos, especialmente entre los más desfavorecidos. Me parece un capítulo claro, valiente y, bajo la apariencia de tratar un tema banal, propone que la educación formal no puede seguir educando (mal) para la sostenibilidad, como hasta ahora. Ya que, como exponen con crudeza Komatsu y Rappleye:

\footnotetext{
We need to radically rethink our starting assumptions about modern mass schooling, one rooted in the modernist western paradigm, and consider whether education is in fact a solution or a cause of the trouble we now face ... it is clear that the Earth does not need more 'educated' consumers of knowledge - a mere refurbishment of the longstanding Western-turned-modern assumption that knowledge alone will allow us to reach the 'good' life. Instead, we must first fundamentally change ways of being, then (re)describe the world including education in those terms. (Komatsu y Rappleye, 2017, p. 168)
}

Finalmente, el capítulo de Patricia Quiroga plantea, siguiendo la propuesta de Van Manen, el tema del tacto pedagógico, que «exige constantemente una intervención correcta, buena o apropiada del educador» (p. 311). Toda renovación pedagógica debe mantener en el corazón de su práctica cotidiana el acompañamiento que Torrent proponía y que Quiroga, con Van Manen, entienden como dar dirección, afecto y protección a los niños y niñas. La autora también recupera en esa atención al tacto, por un lado, la pedagogía que Emmi Pikler desarrolló en el Instituto Lóczy y la conciencia que dar a cada infante el tiempo necesario para conseguir sus logros; y, por el otro, los septenios de

(2) https://en.unesco.org/futuresofeducation/ 
la pedagogía Waldorf en la misma línea del respeto a los ritmos de niñas y niños. El libro termina con un epílogo por parte de los editores en el que defienden el origen y la tradición educativa de la renovación pedagógica ante el concepto de innovación, mucho más vinculado a la economía y a los planteamientos de eficacia y eficiencia educativa. Ante los procesos de mercantilización, de asimilación de calidad con competición, de segregación, etc., los editores apuestan

\begin{abstract}
«por una escuela como dispositivo profundamente democrático y emancipador que nació y existe para proporcionar a cada individuo, independientemente de sus antecedentes étnicos, geográficos, sociales, culturales o económicos, y de sus características y capacidades físicas o psíquicas, el tiempo y el espacio para constituirse como persona libre e independiente, para explorar posibilidades y alternativas hasta entonces inconcebibles». (p. 339)
\end{abstract}

A pesar de formar parte del mismo $y$, por lo tanto, con un claro sesgo, creo que este es un muy buen libro para hacer balance de una década de pulsión renovadora en la educación y, a la vez, plantear una agenda con puntos, métodos, conceptos y propuestas clave para seguir avanzando en ese horizonte de una buena escuela para cada niña, niño, docente, familia, comunidad y planeta. Un libro clave en el debate sobre la renovación pedagógica y sus múltiples orientaciones, objetivos y metodologías.
Referències

Collet, J. (2011) «Educación: ¿arte, burocracia o artesanía? Por una nueva metáfora de la teoría y la práctica educativa». Pedagogia i Treball Social. Revista de Ciències Socials Aplicades, 1, p. 27-50.

Komatsu, H. y Rappleye, J. (2017) «A new global policy regime founded on invalid statistics?» Comparative Education, 53(2), p. 166-191.

Rancière, J. (2000) El maestro ignorante. Barcelona, Laertes.

Sennet, R. (2006) El Artesano. Barcelona, Anagrama. 